\title{
CORRESPONDENCE
}

\section{Doing the maths on the green economy}

In their 21 February report Towards a Green Economy, the United Nations Environment Programme (UNEP) claims that "a green economy grows faster than a [conventional] brown economy, while maintaining and restoring natural capital". We contend that this claim is founded on flawed assumptions.

First, it is based on an inadequate target for reducing energy-related carbon dioxide emissions. The reduction by 2050 under UNEP's G2 greeneconomy scenario is only $35 \%$ relative to 2011 emissions. This cannot achieve the 450 parts per million (p.p.m.) target arising from IPCC's Fourth Assessment, let alone more recent calls for 350 p.p.m. Also, UNEP is assuming that the investment needed to achieve this target is additional to (rather than just a reallocation of) business-as-usual investment funds, ignoring crucial questions about financing. This additional 'green' investment is 10\% higher than that applied to the 'brown' scenario, causing partiality in the analysis.

In addition, the claim hinges on the modelling of the world as a single economy, which overlooks substantial regional inequities and obscures the interplay between economic growth, social justice and climate-change mitigation. Assuming no change in the 2007 15:1 ratio in GDP per capita between high- and low/ medium-income countries, for example, UNEP's G2 scenario requires a rate of decline in average $\mathrm{CO}_{2}$ intensities in both country income groups of $3.9 \%$ per year. By 2050, this would lead to an increase in absolute per capita income differences of US $\$ 104,000$ from $\$ 42,000$ per capita in 2011, and would reduce emissions by only a third.

For full convergence of living standards by 2050 , coupled with the $80 \%$ reduction in global $\mathrm{CO}_{2}$ emissions required to meet a 450 p.p.m. target, we would need a decline in average $\mathrm{CO}_{2}$ intensities in both regions of $8.2 \%$ per year.

Taking these factors into account, we cannot presume that a green economy would grow faster than a brown one.

Peter Victor York University, Toronto, Canada. peter@pvictor.com

Tim Jackson Centre for

Environmental Strategy,

University of Surrey,

Guildford, UK.

\section{Academia resists clean-up in Romania}

A law to reform Romania's education system, approved in February (Nature 469, 142-143; 2011), is already floundering. University staff seem willing to compromise their academic standards when it comes to political matters.

The law bans members of parliament from holding positions of power in universities. But even as the government is busy defining the law's regulations, parliamentarian university rectors from across all the political parties are insisting that the law should not apply to them because they were elected to parliament before the legislation came into effect.

Legal committees of both houses of the Romanian parliament decreed in February that there should be no incompatibility between academic functions and parliamentary positions. But the ministry of education intends to ask the National Integrity Agency, which controls corruption and mismanagement in government, to investigate. Rectors enjoy extra financial benefits when they become parliamentarians, and have the power to maintain the status quo in Romania's inbred, nepotistic and underperforming university system.

To disrupt this system, the next generation of academics needs to be out-bred. External reviewers from academically advanced European Union countries should play a part in overseeing promotions and funding in Romanian universities.

Liviu Giosan Woods Hole Oceanographic Institution, Massachusetts, USA. lgiosan@whoi.edu

\section{Science failed to self-regulate}

As initiators of the open letter that contributed to the resignation of the German defence minister Karl-Theodor zu Guttenberg after allegations of scientific misconduct (Nature 471, 135-136; 2011), we find the reaction of the scientific community disappointing.

Only a handful of senior scientists challenged Chancellor Angela Merkel's point that she had hired a defence minister, not a research assistant: they criticized her for conveying the impression that the issue, and thus academic integrity in general, was politically irrelevant. Some of Germany's most important research institutions took their time to issue cautious statements against the dismissal of fundamental academic principles. A few notable organizations have remained silent.

The affair also raises questions about the relationship between academia and society. Why has it been so hard to convey the importance of academic integrity, given that politicians in Germany and elsewhere regularly proclaim the advantages of the 'knowledge society'? And why did the professional self-regulation of science fail so miserably in the Guttenberg case? This case should mark the beginning, not the end, of a serious debate on academic rigour in Germany. Frederik Trettin, Tobias Bunde University of Konstanz, Germany. frederik.trettin@uni-konstanz.de

\section{Fund biodiversity collections}

Universities are crucial for holding specimen collections in megabiodiverse, developing regions such as Brazil (see Nature 471, 164-165; 2011). Only local institutions can gather information with the necessary resolution to answer biological questions at a regional scale. But such collections suffer from serious funding shortages, mostly because they are not included in a permanent university budget.

A huge volume of material is already stored in university collections throughout Brazil, and these are proliferating as higher education expands in the country. Universities with scientific collections provide a rich environment for recruiting and training evolutionary biologists who will ultimately deal with pressing biodiversity issues. Institutional support would guarantee the collections' continuation beyond the working life of their curators.

The University of São Paulo, Ribeirão Preto, is now uniting its scattered collections into a biodiversity museum - an initiative sparked by a grant of almost US $\$ 800,000$ this year from FAPESP, São Paulo state's research funding agency. Other universities could follow this lead in coordinating biodiversity research to help meet conservation and management priorities.

Flávio A. Bockmann and eight co-authors ${ }^{*}$ University of São Paulo, Ribeirão Preto, Brazil. fabockmann@ffclrp.usp.br ${ }^{*}$ A full list of authors is online at http://dx.doi.org/10.1038/471295d. 